\title{
Transient shock and myocardial impairment caused by phaeochromocytoma crisis
}

\author{
T R D SHAW, P RAFFERTY, G W TAIT \\ From the Department of Cardiology, Western General Hospital, Edinburgh
}

SUMMARY A patient admitted to hospital after injury to the abdomen was found to have transient ${ }_{-}^{\text {? }}$ hypertension which was followed by profound hypotension. ST elevation developed and exten- $-\stackrel{\oplus}{\oplus}$ sive myocardial akinesia was seen at echocardiography, but coronary angiograms at this stageo were normal. After treatment with intravenous fluids and dopamine he progressively recoverednormal cardiac function. A partly necrotic catecholamine secreting tumour was later removed T' from the abdomen and it is likely that a kick to the abdomen had damaged the tumour and the consequent release of catecholamine had triggered a phaeochromocytoma crisis.

Phaeochromocytomas can produce hypotension as well as hypertension, particularly when there has been a sudden release of catecholamines. ${ }^{1}$ In these circumstances the heart may show evidence of myocardial impairment, so-called catecholamine myocarditis. We describe a patient who developed these features after a kick to the abdomen.

\section{Case report}

A 41 year old man was admitted because of abdominal pain after an assault in which he had been kicked in the abdomen and chest. He had generalised abdominal tenderness and haematuria. The results of an urgent Gastrografin meal and intravenous urogram were normal, but ultrasound showed a mass adjacent to the head of the pancreas; this was interpreted as a retroperitoneal haematoma. His pulse was initially regular at 80 beats per minute and there were no abnormal cardiac signs. Blood pressure at admission was $190 / 110 \mathrm{~mm} \mathrm{Hg}$, rising at nine hours later to $240 / 160$. He was given an intravenous dose of hydralazine and the blood pressure settled at $160 / 100 \mathrm{~mm} H \mathrm{Hg}$. The chest $x$ ray film and electrocardiogram were normal.

Forty eight hours after admission signs of low cardiac output developed, but the patient did not

Requests for reprints to Dr T R D Shaw, Department of Cardiology, Western General Hospital, Crewe Road, Edinburgh EH4 2XU. have breathlessness or chest pain. The jugulari venous pressure was not visible. His pulse was 120 方 beats per minute and blood pressure was $100 / 60 \mathrm{~mm} \mathrm{Hg}$, falling one hour later to $60 /$ unrecordable, with no pulsus paradoxus. There $\frac{\AA}{2}$ was a loud gallop rhythm. The electrocardiogram $\stackrel{\vec{F}}{\rightarrow}$ now showed considerable ST elevation (fig la). A응 cross sectional echocardiogram showed akinesia of all areas of the left ventricle except the basal segments. Plasma lactic dehydrogenase concentration reached $4644 \mathrm{U} / 1$ (normal 72-395 U/1). After admin- $-\overparen{\Phi}$ istration of intravenous plasma protein derivative, saline, and dopamine his extremities became warm 3 and his blood pressure rose to $150 / 90 \mathrm{~mm} \mathrm{Hg}$.

On the fourth day after admission the patient started to vomit and his blood pressure became unrecordable. He was cold, clammy, and sweating profusely. A chest $x$ ray film showed slight pul- $\frac{-1}{8}$ monary congestion. Dopamine infused at a higher? rate than the previous infusion increased the blood N pressure, which fluctuated between $180 / 70$ and $65 /$ unrecordable $\mathrm{mm} \mathrm{Hg}$, while heart rate varied between 80 and 130 beats per minute. Considerable $e^{\omega}$ ST elevation $(5 \mathrm{~mm})$ persisted without development of $Q$ waves. To establish whether the heart showed evidence of traumatic damage the patient underwente cardiac catheterisation. Initial aortic and left ven:tricular pressures were $55 / 40$ and $55 / 0-4 \mathrm{~mm} \mathrm{Hg}$ One and a half litres of plasma protein derivative andD $500 \mathrm{ml}$ of saline were infused intravenously over $20 \%$ minutes. The aortic and left ventricular pressures rose to $160 / 95$ and $160 / 10-35 \mathrm{~mm} \mathrm{Hg}$. Right atriak 


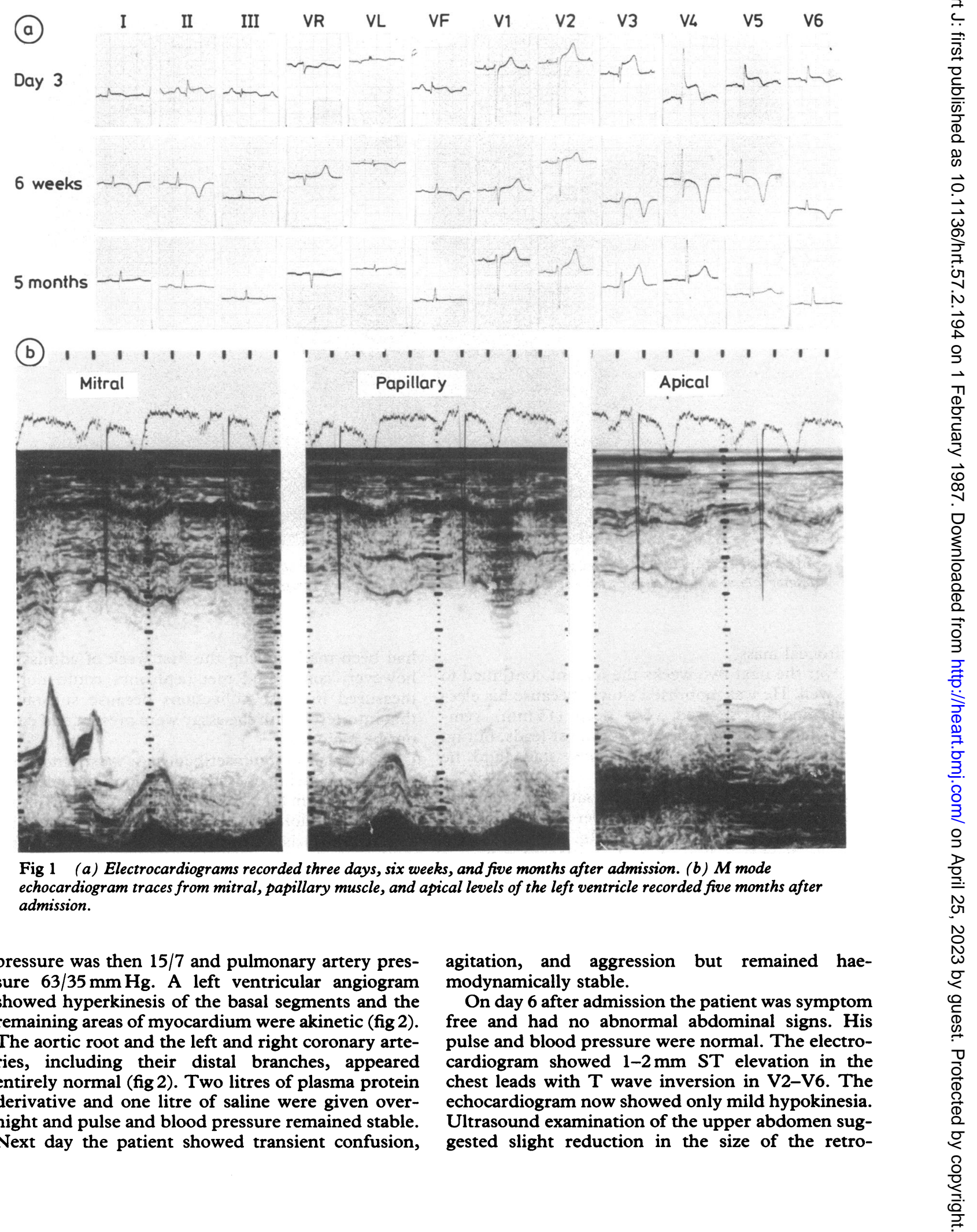




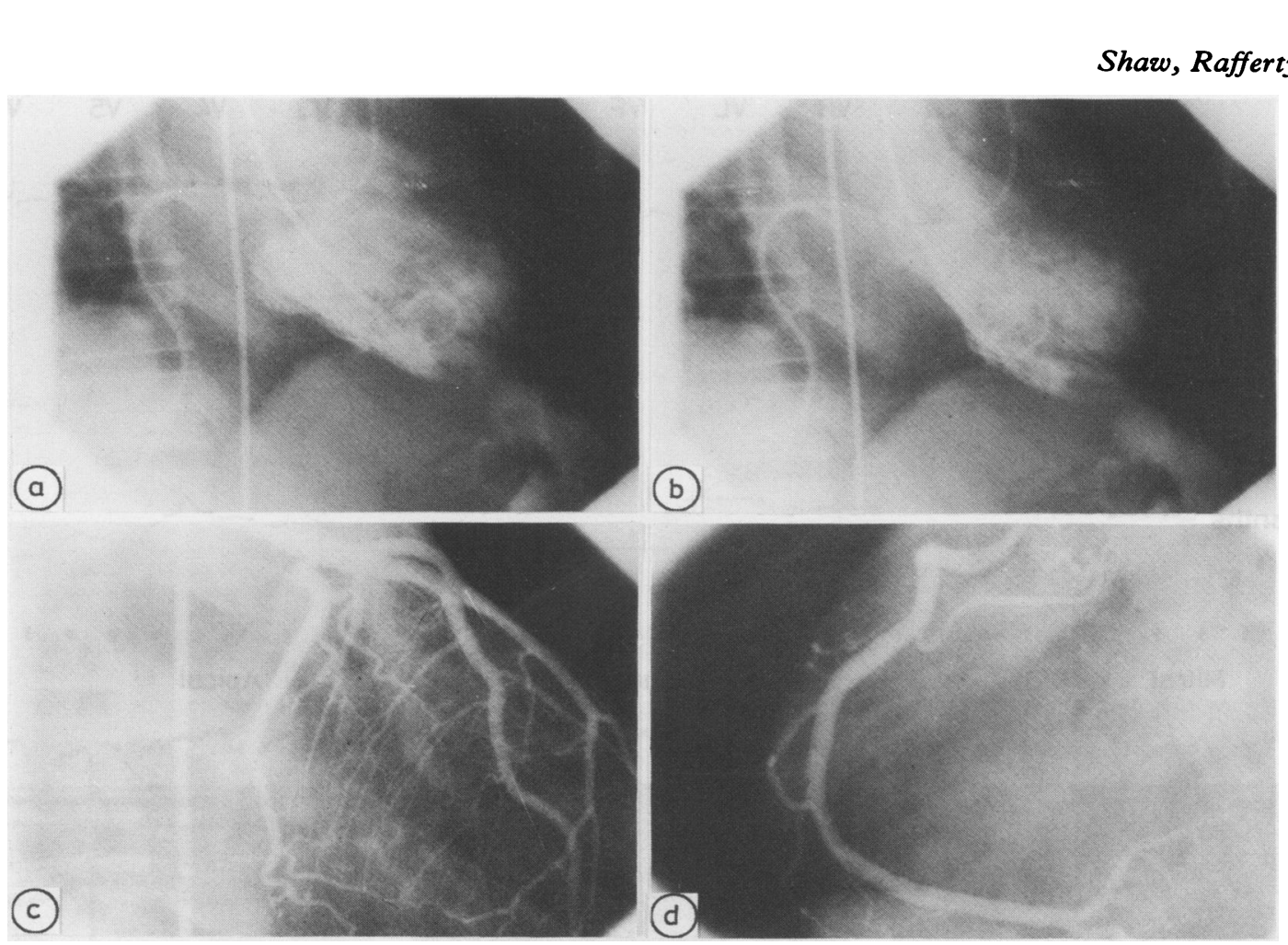

Fig 2 (a) Left ventricular angiogram at end diastole ( $30^{\circ}$ right anterior oblique view) (b) left ventricular angiogram at end systole, (c) left coronary angiogram, and (d) right coronary angiogram.

peritoneal mass.

Over the next two weeks the patient continued to feel well. He was mobilised slowly because his electrocardiogram showed very deep $(15 \mathrm{~mm})$ symmetrical $T$ wave inversion in the chest leads, but no arrhythmias had appeared at any stage and he remained normotensive.

At outpatient review six weeks after admission he was in sinus rhythm at 58 beats per minute and had a blood pressure of $122 / 78 \mathrm{~mm} \mathrm{Hg}$. There were no abnormal cardiac signs. An echocardiogram showed normal myocardial contraction but the electrocardiogram still showed deep $T$ wave inversion (fig la). Ultrasound examination of the upper abdomen showed persistence of the retroperitoneal mass. Computed tomography of the abdomen showed a mass that lay anteromedial to the right kidney and inferior to the head of the pancreas. Both adrenal glands appeared normal. An ${ }^{131}$ I-metaiodobenzyl guanidine isotope scan did not show any uptake at the site of the mass. Three 24 hour urine collections, however, showed an increase in urinary concentrations of conjugated metanephrines $(5 \cdot 6,3 \cdot 6$, and $7.4 \mu \mathrm{mol} / 1$; reference range $0-3 \mu \mathrm{mol} / 1)$. Three 24 hour urine collections for metanephrine estimation had been made during the first week of admission however, conjugated metanephrines could not be measured in these collections because substances that interfered with the assay were present and could not be removed.

A $3 \mathrm{~cm}$ hard circumscribed mass was removed at operation. During operation the blood pressure rose to $230 / 130 \mathrm{~mm} \mathrm{Hg}$; this was controlled by intravenous labetolol. Transient agitation and aggression occurred two days after operation. The cut surface of the tumour was yellow with a necrotic centre and in formalin it turned dark brown. Light microscespy showed extensive central necrosis with peripheral areas of viable chromaffin cells. Electron microscoby confirmed the presence of membrane-bound secretory granules.

After operation the patient was physically well \&ut he still had intermittent psychiatric symptoms. Urinary metanephrine concentration returned? to normal. Five months after admission the $T$ wave inversion of the electrocardiogram had disappeared (fig la). An echocardiogram confirmed a return to normal left ventricular contraction in all segments (fig 1b). 


\section{Discussion}

This patient had a phaeochromocytoma crisis with a short hypertensive phase and a longer hypotensive phase. It may seem paradoxical that a low blood pressure can complicate a phaeochromocytoma but orthostatic hypotension is often seen in phaeochromocytoma patients who have hypertension when supine. Severe hypotension can be precipitated by induction of anaesthesia or by operation. ${ }^{1}$ Blood volume is reduced in these cases and this is thought to be the result of a high sympathetic tone ${ }^{2}$ or a state of autonomic dysfunction simulating ganglionic block. ${ }^{3}$ A decrease in adrenocortical hormone has also been suggested as a factor. ${ }^{4}$ Withdrawal of high catecholamine concentrations by removal of a phaeochromocytoma can also induce a severe hypotension which is associated with low intracardiac filling pressures. ${ }^{1}$ Maintaining an adequate blood volume is therefore important in the perioperative management of phaeochromocytomas. Patients may also present in a hypotensive crisis. ${ }^{5}$ Hypotension is an ominous sign when phaeochromocytoma is present. Van Vliet $e t$ al found that eight of 11 deaths followed a period of hypotension. ${ }^{6}$ In our patient severe hypotension developed 48 hours after admission. It responded to large doses of intravenous fluids and dopamine.

The hypotension with phaeochromocytoma may be aggravated by myocardial impairment caused by high circulating catecholamine concentrations. The ability of adrenal extracts to create myocardial damage has been studied since the beginning of the century. ${ }^{7}$ Van Vliet et al examined the myocardial structure in 26 necropsy cases with phaeochromocytoma. $^{6}$ Fifteen showed evidence of "active catecholamine myocarditis", the histological features of which were $(a)$ focal degeneration and necrosis of myocardial fibres, (b) foci of inflammatory cells, $(c)$ a diffuse oedema, and $(d)$ an increase in fibrous tissue. Oedematous thickening of the small and medium sized arteries with partial fibrous replacement of the smooth muscle of the media was seen in a few of these cases. Most (24/26) showed left ventricular hypertrophy. Similar findings have been found in animals given noradrenaline or adrenaline and in patients receiving catecholamine treatment. ${ }^{7}$ The clinical features of these abnormalities take various forms. In stable patients, cardiomegaly, electrocardiographic evidence of left ventricular hypertrophy, and $T$ wave inversion are common. ${ }^{68}$ Atrial and ventricular arrhythmias may occur. Phaeochromocytomas occasionally can be present in patients with normal blood pressure but with features of a chronic congestive cardiomyopathy that improves with removal of the tumour. ${ }^{6910}$ More dramatically, the patient may present with electrocardiographic evidence of ST elevation and deep symmetrical $T$ wave inversion that resembles myocardial infarction. ${ }^{68911-15}$ The myocardium can subsequently return to normal ${ }^{13}$ but aneurysm formation (with normal coronary arteries) has also been reported. ${ }^{15}$ In our patient extensive left ventricular akinesia was shown by echocardiography and angiography for over 24 hours but normal contraction subsequently returned. The metabolic basis for such prolonged but temporary myocardial impairment is unclear. No coronary artery spasm was seen at this stage although ST segment elevation was present.

This patient's management was also complicated by acute psychiatric abnormality. An association between phaeochromocytoma and abnormal psychological states has been reported elsewhere. ${ }^{16-18}$

After recovery, our patient remained normotensive but had raised 24 hour urinary concentrations of metanephrine. A catecholamine secreting tumour with extensive necrosis was subsequently removed from the para-aortic area. Approximately $10 \%$ of phaeochromocytomas lie outside the adrenal glands. ${ }^{1}$ The mass had initially been attributed to a retroperitoneal haematoma caused by the kicks to his abdomen. In three collections of urine for metanephrine assay during his first week of admission there was interference by unknown substances. Dopamine and other drugs had been given during that period. Stress and drugs can affect urinary metanephrine results and it is possible that necrosis of the tumour had released precursors and metabolites of catecholamines. An ${ }^{131}$ I-metaiodobenzylguanidine scan has been useful for localising phaeochromocytomas but was negative in this case. ${ }^{19}$

External pressure, even from bending, can cause release of catecholamines from phaeochromocytoma ${ }^{1}$ and severe necrosis or haemorrhage within a phaeochromocytoma has been shown to produce shock. ${ }^{20-22}$ We believe that a kick to this patient's abdomen caused tumour necrosis and a massive release of catecholamines which led to his initial hypertension and the subsequent hypotension and myocardial impairment.

We thank Dr D B Horn and Dr J N Webb for their help.

\section{References}

1 Levine SN, McDonald JC. The evaluation and management of pheochromocytomas. Adv Surg 1984;17:281-313.

2 Brunjes S, Johns VJ Jr, Crane MG. Pheochromo- 
cytoma: postoperative shock and blood volume. N Engl f Med 1960;262:393-6.

3 Engleman K. Phaeochromocytoma. Clin Endocrinol Metab 1977;6:769-97.

4 Delarue NC, Morrow JD, Kerr JH, Colapinto RF. Pheochromocytoma in the modern context. Can $\mathcal{f}$ Surg 1978;21:387-94.

5 McManus BM, Fleury TA, Roberts WC. Fatal catecholamine crisis in pheochromocytoma: curable cause of cardiac arrest. Am Heart $\mathcal{F} 1981$;102:930-2.

6 Van Vliet PD, Burchell HB, Titus JL. Focal myocarditis associated with pheochromocytoma. $N$ Engl f Med 1966;274:1102-8.

7 Hapt JI. Cardiovascular injury induced by sympathetic catecholamines. Prog Cardiovasc Dis 1974;17:73-86.

8 Sutton MGStJ, Sheps SG, Lie JT. Prevalence of clinically unsuspected pheochromocytoma: review of a 50-year autopsy series. Mayo Clin Proc 1981;56:354-60.

9 Baker G, Zeller NH, Weitzner S, Leach JK. Pheochromocytoma without hypertension presenting as cardiomyopathy. Am Heart $\mathcal{f}$ 1972;83:688-93.

10 Velasquez G, D'Souza VJ, Hackshaw BT, Glass TA, Formanek AG. Phaeochromocytoma and cardiomyopathy. $\mathrm{Br} \mathcal{F}$ Radiol 1984;57:89-92.

11 Pelkonen R, Pitkanen E. Unusual electrocardiographic changes in pheochromocytoma. Acta Med Scand 1963;173:41-4.

12 Radtke WE, Kazmier FJ, Rutherford BD, Sheps SG. Cardiovascular complications of pheochromocytoma crisis. Am $\mathcal{f}$ Cardiol 1975;35:701-5.

13 Bouchez C, Ostermann G, Hecart J, Elaerts J, Bajolet A. Les manifestations cardiaques des pheochromo- $f$ cytomes. Arch Mal Coeur 1979;72:90-5.

14 Menozzi C, Monducci I, Vergoni W, Lolli G, Gheller 흔 G, Casali G. Infarto miocardico acuto in soggetti $\frac{\bar{s}}{\partial}$ giovani quale manifestazione di feocromocitoma: a $\mathbb{\Phi}$ proposito di due casi. G Ital Cardiol 1982;12:604-8.

15 McGonigle P, Webb SW, Adgey AAJ. Phaeochromo- 0 cytoma: an unusual cause of chest pain. $\mathrm{Br}$ Med $\mathcal{F}$ 1983;286:147-8.

16 Gillmer RE. Phaeochromocytoma -an interesting $\vec{\omega}$ psychiatric presentation. $S$ Afr Med $\mathcal{F}$ 1972;46: 174-6.

17 El Matri A, Slim R, Zmerli S, Ben Ayed H. نु Pheochromocytome avec troubles psychiatriques: un iv cas. Nouv Presse Med 1978;7:1467-70.

18 Bahemuka M. Phaeochromocytoma with schizophreniform psychosis. Br f Psychiatry 1983;142:422-3.

19 Valk TW, Frager MS, Gross MD, et al. Spectrum of pheochromocytoma in multiple endocrine neoplasia: $T$ a scintigraphic portrayal using ${ }^{131}$ I-metaiodo- $\frac{D}{O}$ benzylguanidine. Ann Intern Med 1981;94:762-7.

20 Huston JR, Stewart WRC. Hemorrhagic pheochromocytoma with shock and abdominal pain. Am f Med 1965;39:502-4.

21 Delaney JP, Paritzky AZ. Necrosis of a pheochromocytoma with shock. $N$ Engl f Med 1969;280:1394-5.

22 Jones DJ, Durning P. Phaeochromocytoma presenting as an acute abdomen. $\mathrm{Br} \mathrm{Med} \mathcal{F} 1985 ; 291: 1267-8$. 